\title{
Multilayer Framework for Vehicle-to-Grid Operation
}

\author{
Diyun $\mathrm{Wu}, \mathrm{K}$. T. Chau, and Shuang Gao \\ Department of Electrical and Electronic Engineering \\ The University of Hong Kong \\ Hong Kong \\ dywu@eee.hku.hk
}

\begin{abstract}
In recent years, electric vehicles (EVs) have been widely accepted by general publics due to their low emissions. Particularly, those EVs which are able to be connected to power grid have earned lots of attention. In this paper, a multilayer framework is newly proposed for vehicle-to-grid operation. In this framework those gridable EVs can serve as resources to provide their capacity and energy service or as loads to be charged directly. The corresponding aggregator works as a smart controller for the framework, which is responsible for forming aggregations of gridable EVs and determining which vehicle to be a resource or a load. Cost-emission analysis is carried out based on this framework. Hence, operation cost and emissions can be reduced by using these gridable EVs.
\end{abstract}

Keywords- electric vehicle; plug-in hybrid vehicle; vehicle-togrid; smart grid

\section{INTRODUCTION}

With the increase of air pollution, environment problems have increased rapidly since past decade. Some of them are serious problems which can influence human society, such as global warming. One major source of air pollution can be attributed to vehicle emissions [1]. Currently, vehicle usage not only intensifies oil demand, but also aggravates the pollution. Since electric vehicles (EVs) can highly reduce the emissions compared with traditional gasoline vehicles, EVs will play an important role for the transportation market in future [2]-[9].

Vehicle-to-grid (V2G) technology has been proposed recently. It is a bi-directional electrical grid interface that allows a gridable EV to take energy from the grid or put it back on the grid. At present, there are three kinds of gridable EVs, namely the battery EV, plug-in hybrid EV and range-extended EV. Batteries on these kinds of gridable EVs can serve as bidirectional portable power plants. Therefore they can store energy while parking, and are able to feed power back to the grid via power converters [10]-[17].

\section{CONCEPT OF $\mathrm{V} 2 \mathrm{G}$}

The basic concept of $\mathrm{V} 2 \mathrm{G}$ is that gridable EVs can charge from the power grid when power demand is low and can discharge to supply the grid when power is required. Daily load changes greatly at different hours. Some small and expensive generators have to be started up to fulfill the power demand at peak hours. Power system will be more stable and reliable and have lower costs by utilizing the V2G concept. As shown in Fig. 1, during the off-peak conditions at night, gridable EVs are considered as loads by being charged from the grid, hence leveling the low load [18]. During the peak conditions at daytime, they can feed back power to shave the peak load. In this case, people can plug-in their gridable EVs at night when electricity is cheap, and then plug-in during the daytime to sell electricity at a profit when electricity is expensive [19]. Thus, V2G helps solve the major problem that demand for electricity is high during the daytime when everything from industrial plants to air conditioning is running full blast and excess electricity is wasted at night.

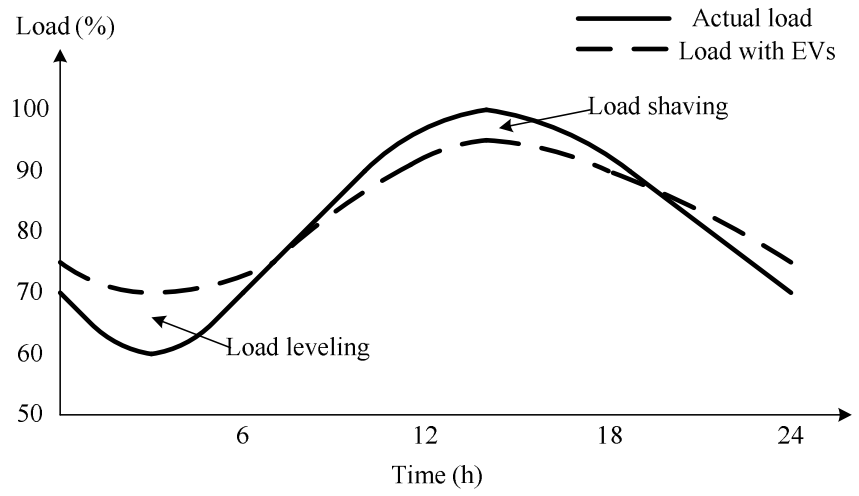

Figure 1. Daily load with and without EVs.

This paper proposes a multilayer framework of V2G concept. Before introducing the framework, two characteristics of V2G should be taken into account. Firstly, the capacity of the batteries on gridable EVs is usually $5-20 \mathrm{kWh}$. A single gridable EV cannot be a storage or generation device to the grid due to its small storage capacity. However a number of gridable EVs aggregated in a parking lot or service station can provide considerable energy to the power grid. Generally a multi-storey parking lot has about 300 parking places. If it is fully parked by gridable EVs, the maximum power capacity is up to $6 \mathrm{MWh}$ and remarkable to the grid. Therefore the framework is based on the aggregation of gridable EVs.

Secondly V2G power should be utilized pertinently. According to the characteristics of EVs, V2G power is suitable for quick response, which refers to regulation of fluctuation in load and compensation of unexpected device failures [20]. V2G can perform instantaneous backup of intermittent renewable power. It is suitable to save high cost electrical 
equipment but not appropriate for providing base load power which can be supplied economically by large and continuously running generators.

\section{PROPOSED FRAMEWORK}

Since this framework is based on the aggregation of a large number of gridable EVs, the aggregator is introduced, which is responsible for collecting EVs and making them maintain a certain level to interact with the grid. In this case, information technology will play a great role in this framework. Gridable EVs can act as resources or loads.

Fig. 2 shows a recently developed V2G framework [21]. When the aggregated EVs act as resources, a significant capacity produced by them can affect the grid operator such as the independent system operator (ISO) and regional transmission organization (RTO). The control signal from ISO/RTO which operates the bulk power system delivers the requests for power to the aggregated EVs through the aggregator. When the aggregated EVs act as loads, they also send the requests for being charged to the energy service provider (ESP) through the aggregator. The intergrid consists of the aggregator, ISO/RTO and ESP. The communication between them forms the foundation of $\mathrm{V} 2 \mathrm{G}$ network.

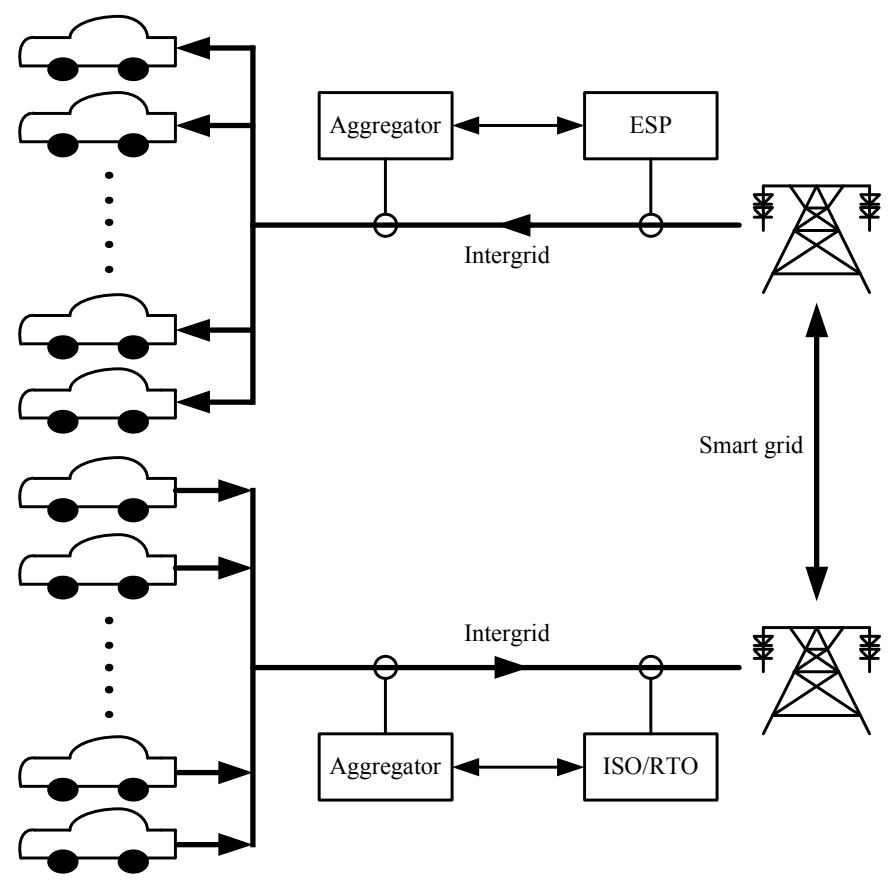

Figure 2. Recent framework of V2G.

The aggregator contacts with ISO/RTO and ESP directly instead of the aggregated EVs. The aggregator manages the capacity and energy service collected by the aggregation of EVs, and dispatches the aggregated EVs either to sell their capacity and energy service to the grid or to be charged from the grid.

A new $\mathrm{V} 2 \mathrm{G}$ framework is proposed in this paper. An intragrid is newly introduced to make a multilayer framework of $\mathrm{V} 2 \mathrm{G}$ as shown in Fig. 3. The aggregator in this framework not only is responsible for collecting a certain number of gridable EVs into a single entity but also plays the role of controlling the power flow inside the intragrid. The aggregation of EVs in this framework is capable of supplying capacity and energy service requested by power grid. Meanwhile it can be connected to ESP to be charged from the grid.

The intragrid consists of these aggregated EVs, which exists for satisfying the electrical energy need inside the entity of aggregated EVs. The aggregated EVs should still be both of resources and loads. However, when they act as resources, they not only provide capacity and energy service to the grid but also supply the other vehicles' request for energy in the intragrid. On the other hand, when they act as loads, it will be more convenient for them to be charged from the other EVs in the intragrid if allowed.

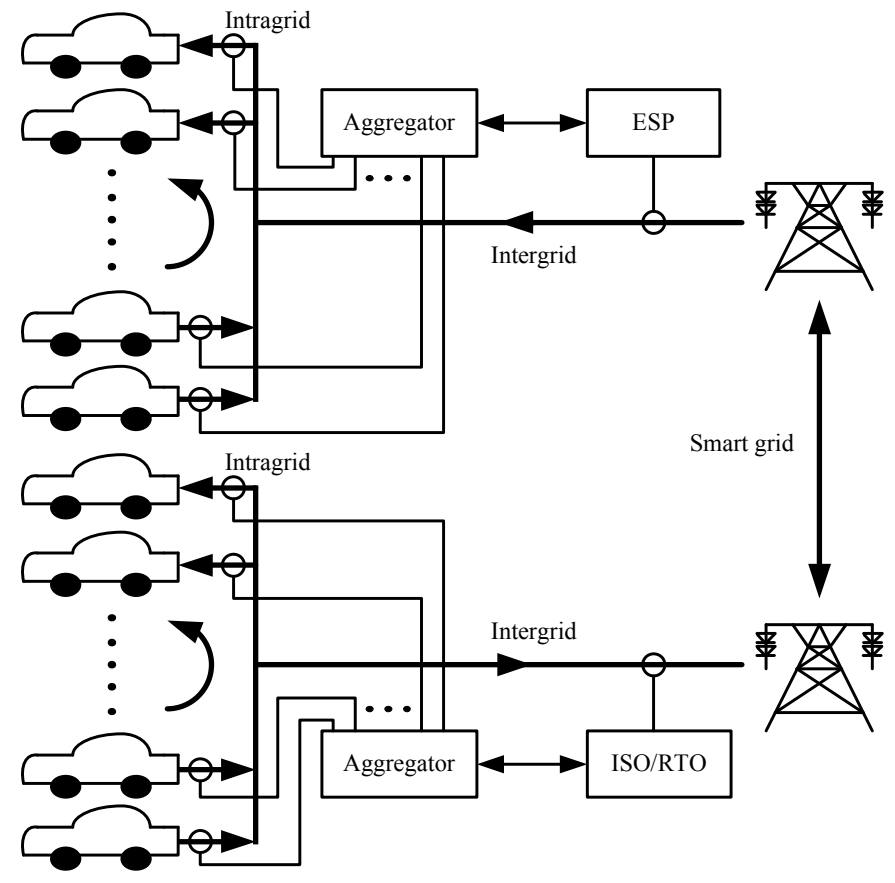

Figure 3. Proposed multilayer framework of V2G.

The aggregator plays an important part in this multilayer framework. It is in charge of the intergrid and intragrid in the meantime. The aggregator artfully controls the connection between the aggregation of EVs and ISO/RTO or ESP, and between a single EV and every other one. The request of individual EV will be processed in the intragrid first. This EV should be charged from some other EVs if the collected capacity inside the intragrid allows. No signal will be sent by the aggregator to the ESP. Those EVs whose status allows to selling power out can be operated by the aggregator to provide power to the needed EVs inside the intragrid. Thus, unnecessary trading with the ISO/RTO can be avoided.

The aggregator also has the function of determining which EVs should participate in the aggregation. In general, the participation depends on their state of charge [22]-[27], and the optimal time and location that EVs can be connected to serve for the grid. Notice that the aggregation not necessarily consists of the EVs from the same parking lot or service station. 
Based on this multilayer framework of $\mathrm{V} 2 \mathrm{G}$, the logical connection for communication with ISO/RTO and ESP is necessary. For customers, on-board metering of the amount of selling or charging determined by the state of charge is indispensable. All these requirements refer to communication skills which are also the basis of smart grid. The signals transmit in these grids may be a broadcast radio signal, or through a cell phone network, direct internet connection, or power line carrier [28]. Effective communication ensures these grids steady and reliable.

\section{COST-EMISSION OPTIMIZATION}

Based on this multilayer framework of V2G, operation cost and emissions can be reduced by intelligently and efficiently scheduling the aggregation of gridable EVs and traditional generating units. The cost-emission optimization analysis refers to minimize the operation cost and emissions as well as to improve system reserve and reliability.

Generally base load power is provided by large and continuously running generating units which have slower ramp rates. Nevertheless small generating units and gridable EVs have faster ramp rates. Therefore, the key of cost-emission optimization is to properly scheduling those small generating units and gridable EVs. Although gridable EVs can perform instead of some small and expensive generators, a large number of EVs may cause high cost [29]-[31]. The objective of the scheduling optimization is to make the balance of profit, emissions and reliability of power system and minimize the cost and emissions.

In this paper, fuel cost, start-up cost and shut-down cost are considered as operation cost of power system. All these costs and emissions can be expressed by the following functions [32].

- Fuel cost:

$$
F C_{i}\left(P_{i}(t)\right)=a_{i}+b_{i} P_{i}(t)+c_{i} P_{i}^{2}(t)
$$

- $\quad$ Start-up cost:

$$
\begin{gathered}
S C_{i}(t)=\left\{\begin{array}{cc}
h-\cos t_{i} & M D_{i} \leq X_{i}^{\text {off }}(t) \leq H_{i}^{\text {off }} \\
c-\cos t_{i} & X_{i}^{\text {off }}(t)>H_{i}^{\text {off }}
\end{array}\right. \\
H_{i}^{\text {off }}=M D_{i}+c-s-\text { hour }_{i}
\end{gathered}
$$

- Shut-down cost:

The shut-down cost does not vary with other parameters, and it is usually considered as zero for standard power systems.

- Emissions:

$$
E C_{i}\left(P_{i}(t)\right)=\alpha_{i}+\beta_{i} P_{i}(t)+\gamma_{i} P_{i}^{2}(t)
$$

The fuel cost and emissions are expressed as second order functions, where $P_{i}(t)$ represents the output power of $i$ th unit at time $t, F C_{i}(), S C_{i}(), E C_{i}()$ represent the fuel cost function, startup cost function and emissions function of unit $i$ respectively, $h-\cos t_{i}$ and $c-\cos t_{i}$ represent the hot start-up cost and cold start-up cost of $i$ th unit respectively, $c-s-$ hour $_{i}$ represents the cold start hour of $i$ th unit, $M D_{i}$ represents the minimum down time of $i$ th unit, $X_{i}^{\text {off }}(t)$ represents the duration of continuously off of $i$ th unit at time $t, a_{i}, b_{i}, c_{i}$ are positive fuel cost coefficients of $i$ th unit, and $\alpha_{i}, \beta_{i}, \gamma_{i}$ are emission coefficients of $i$ th unit.

The fitness function for cost-emission optimization of $\mathrm{V} 2 \mathrm{G}$ system is given by:

$$
\begin{aligned}
& \min T C=w_{c} \times(\text { Fuel }+ \text { Start }-u p)+w_{e} \times \text { Emission } \\
& =\sum_{i=1}^{N} \sum_{t=1}^{H}\left[w_{c}\left(F C_{i}\left(P_{i}(t)\right)+S C_{i}\left(1-I_{i}(t-1)\right)\right)+w_{e}\left(\psi_{i} E C_{i}\left(P_{i}(t)\right)\right)\right] I_{i}(t)
\end{aligned}
$$

where $N$ is the number of units, $H$ is the scheduling hours, $I_{i}(t)$ represents the status of $i$ th unit at time $t$ which is binary ( 1 for on, 0 for off), $w_{c}, w_{e}$ are weight factors which equal 1 when cost or emission are included and equal 0 when they are not included in the fitness function, and $\psi_{i}$ is the emission penalty factor of $i$ th unit.

Therefore, the cost-emission analysis of $\mathrm{V} 2 \mathrm{G}$ system is an optimization problem, in which there are limited and restricted parking lots and a large number of gridable EVs. Moreover, a lot of constraints should be satisfied, such as forecast load demand, parking lot limitations, state of charge of gridable EVs, charging-discharging efficiency, and spinning reserve requirement. This is a complicated constrained optimization problem.

\section{PARTICLE SWARM OPTIMIZATION}

In this paper, particle swarm optimization (PSO) is used to solve this complicated constrained optimization problem. The system is initialized with a population of random solutions and searches for optima by updating generations. In PSO, particles are the potential solutions, which fly through the problem space by following the current optimum particles. Each particle keeps track of its coordinates in the problem space which are associated with the best solution (fitness) it has achieved so far. The fitness value is stored as pbest. Another value lbest is the best value obtained so far by any particle in the neighbors of the particle. When a particle takes all the population as its topological neighbors, there is a global best gbest. At each time step, PSO changes the velocity of accelerating each particle toward its pbest and lbest locations. Acceleration is weighted by a random term, with separate random numbers being generated for acceleration toward pbest and lbest locations. It is demonstrated that PSO gets better results in a faster, cheaper way compared with other methods [33].

According to the PSO, after finding the two best values, the particle updates its velocity and positions by using the following equations:

$$
\begin{gathered}
v[]=v[]+c 1 \times \operatorname{rand}() \times(\text { pbest }[]-\operatorname{present}[])+c 2 \times \operatorname{rand}() \\
\times(\operatorname{gbest}[]-\operatorname{presen} t[]) \\
\quad \text { present }[]=\operatorname{present}[]+v[]
\end{gathered}
$$

where $v[]$ is the particle velocity, present [] is the current particle, pbest [] and gbest [] are defined as stated before, rand () is a random number between $(0,1)$, and $c 1$ and $c 2$ are learning factors. 
A particle $P_{i}$ consists of the generating unit which is an $N \times H$ binary matrix $X_{i}$, the gridable EVs which are an $H \times 1$ integer column vector $Y_{i}$, the velocity which is an $(N+1) \times H$ real valued matrix $V_{i}$, and the fitness which is a real-valued cost $T C$. Therefore, the dimension of particle $P$ is $(N+1) \times H$. The position and velocity mentioned above are presented as $x_{i j t}$ and $v_{i j t}$, where $i$ is the particle number, $j$ is generating unit or the number of gridable EVs and $t$ is time. The velocity changes with iterations. In this case, for gridable EVs, the velocity $v_{i j t}$ and position $x_{i j t}$ can be calculated by using the following equations:

$$
\begin{gathered}
v_{i j t}=\left[v_{i j t}+c 1 \times \text { rand } 1 \times\left(\text { pbest }_{i j t}-x_{i j t}\right)+c 2 \times \text { rand } 2\right. \\
\left.\times\left(\text { gbest }_{j t}-x_{i j t}\right)\right]\left[1+\frac{- \text { Range }}{\operatorname{Max}(k)}(k-1)\right] \\
x_{i j t}=x_{i j t}+v_{i j t}
\end{gathered}
$$

where rand 1 and rand 2 are random numbers between $(0,1)$, Range is the balancing factor which can balance the velocity of global search and local search, and $k$ is the number of iterations.

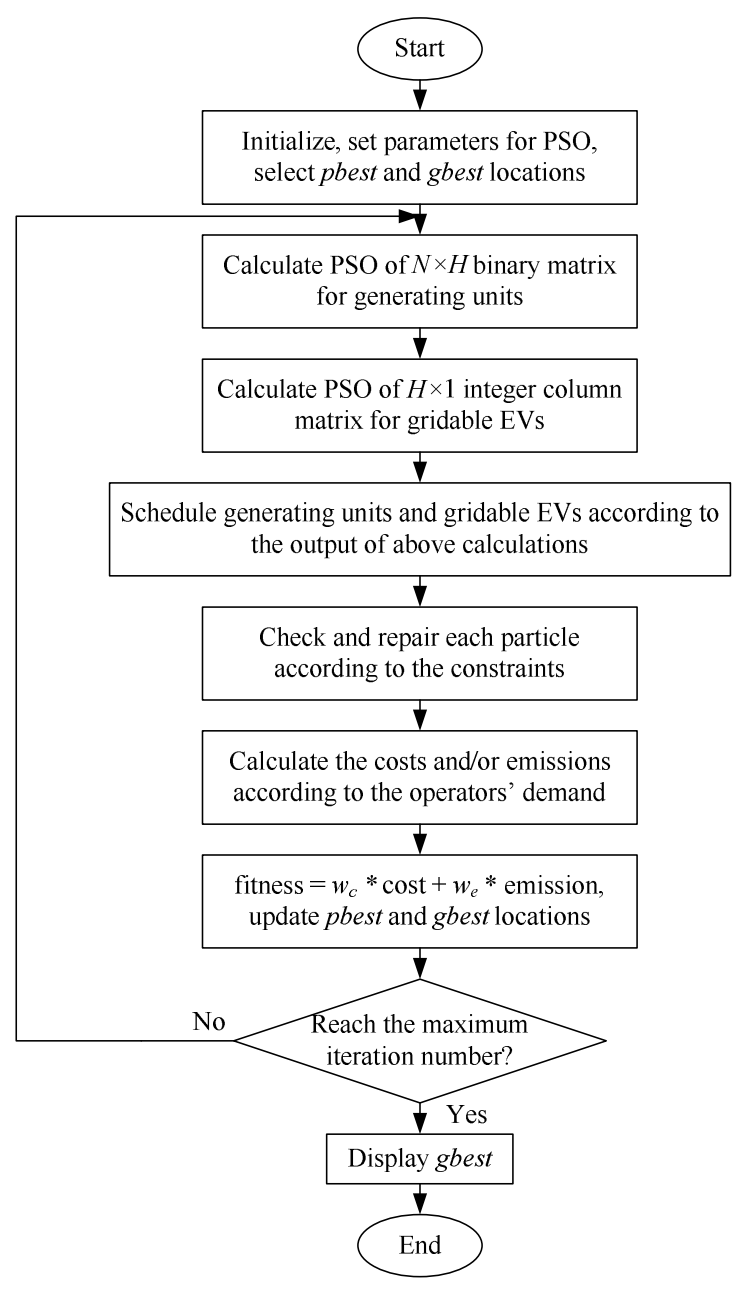

Figure 4. Flowchart of cost-emission PSO of V2G system.
PSO is applied for both optimization of generating units and gridable EVs. The flowchart of the entire system using PSO is shown in Fig. 4.

\section{SimUlation RESUlTS}

In this paper, a system including 10 generating units and maximum 1000 available gridable EVs is considered for costemission optimization simulation. All the gridable EVs are ideally considered charging by renewable energy to make sure the emission can be minimal. The average battery capacity of gridable EV is $15 \mathrm{kWh}$. The population size of PSO is set to 30; the maximum number of iterations (epochs) is set to 1000; and the acceleration constants $c 1$ and $c 2$ are 1.5 and 2.5 respectively.

Cost-emission optimization simulation is performed on three different conditions which are $w_{c}=1$ while $w_{e}=1, w_{c}=0$ while $w_{e}=1$, and $w_{c}=1$ while $w_{e}=0$. Namely, the cost-emission optimization is run in the situations both cost and emission are considered in the fitness function, only the emission is considered in the fitness function and only the cost is considered in the fitness function.

Fig. 5 shows the effect when both cost and emission are considered in the fitness function. In Fig. 5(a), the fitness represents the total cost of the system since it equals cost plus emission. The total cost decreases and ultimately converges. Fig. 5(b) and Fig. 5(c) shows the variations of cost and emission respectively. Though cost and emission fluctuates, they get stable gradually with the number of iterations increasing.

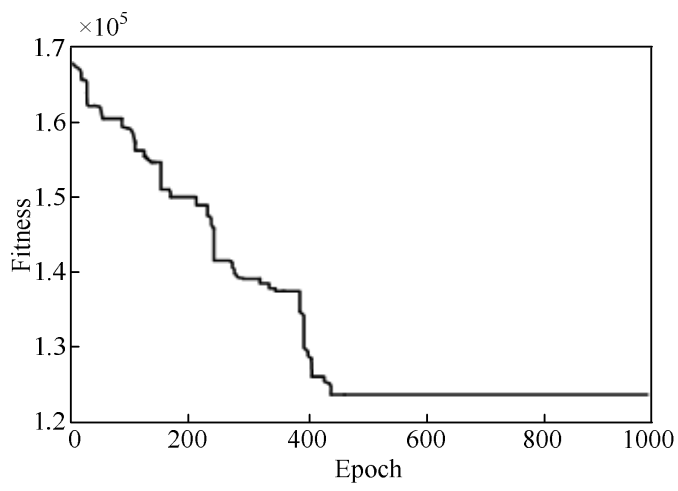

(a)

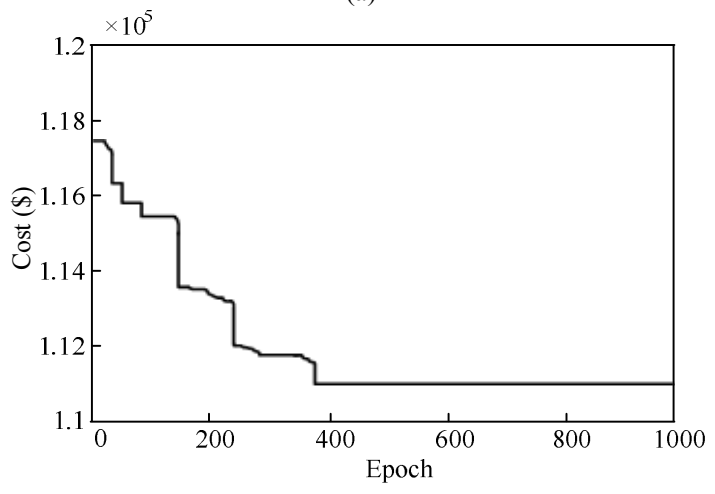

(b) 


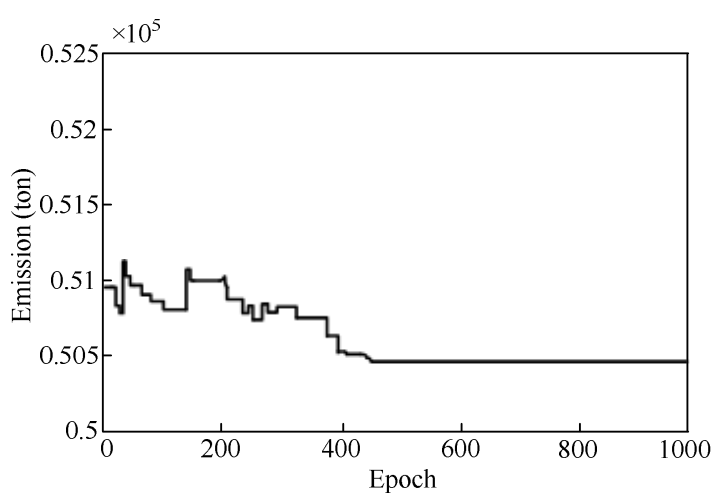

(c)

Figure 5. Effect of cost plus emission in fitness function.

Fig. 6 shows the effect when only emission are considered in the fitness function. In Fig. 6(a), the fitness represents the emission of the system since the cost is ignored in the fitness function. Fig. 6(b) shows the operation cost of the system. Compared with the results of the situation both cost and emission work, the emission is reduced greatly. However, the operation cost is high, which means those small and expensive generating units need to work even at off-peak hour while V2G may not be working. For practical systems, this kind of results may not be acceptable.

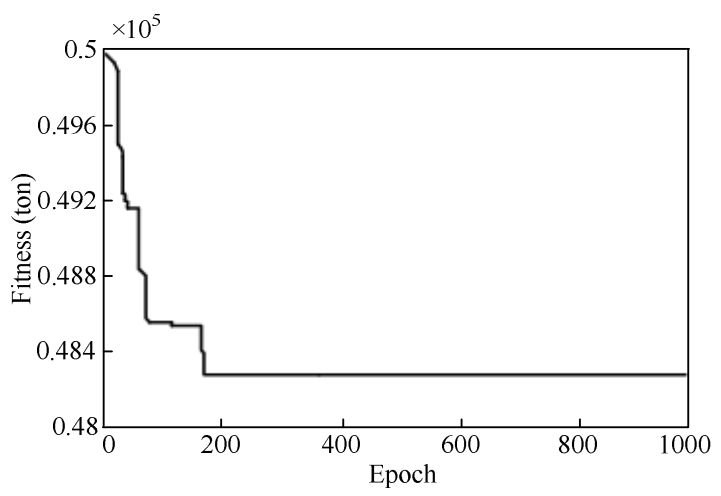

(a)

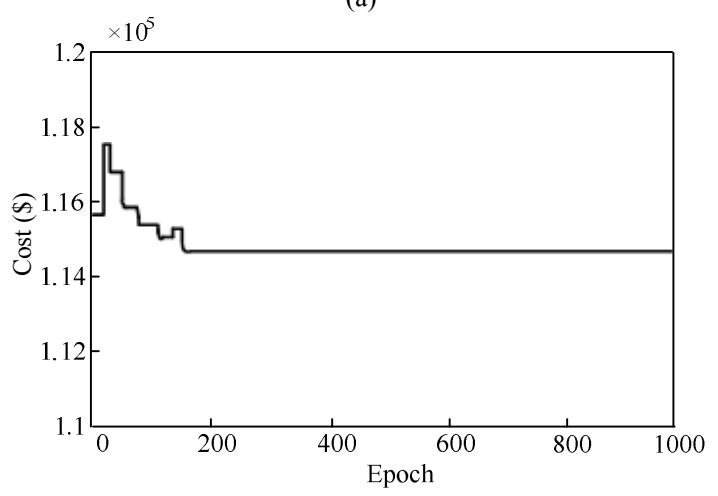

(b)

Figure 6. Effect of only emission in fitness function.

Fig. 7 shows the effect when only cost are considered in the fitness function. In Fig. 7(a), the fitness represents the operation cost of the system since the emission is ignored in the fitness function. Fig. 7(b) shows the emission of the system. Compared with the previous results, the operation cost decreases rapidly and keeps low. However, the emission fluctuates fiercely and is very high which definitely cannot be accepted by environment.

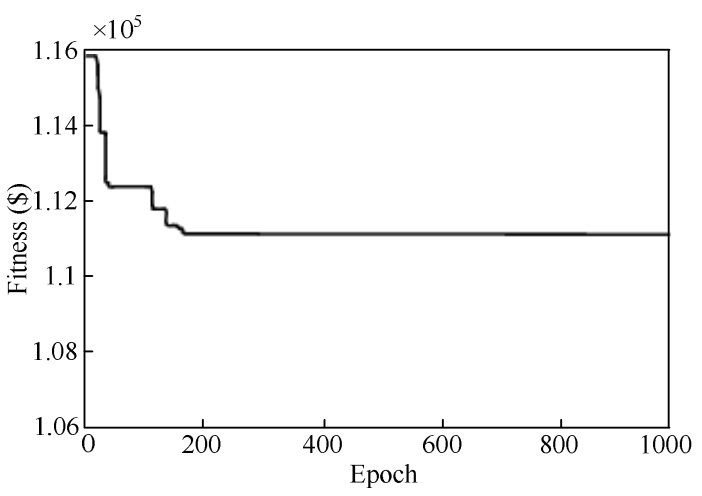

(a)

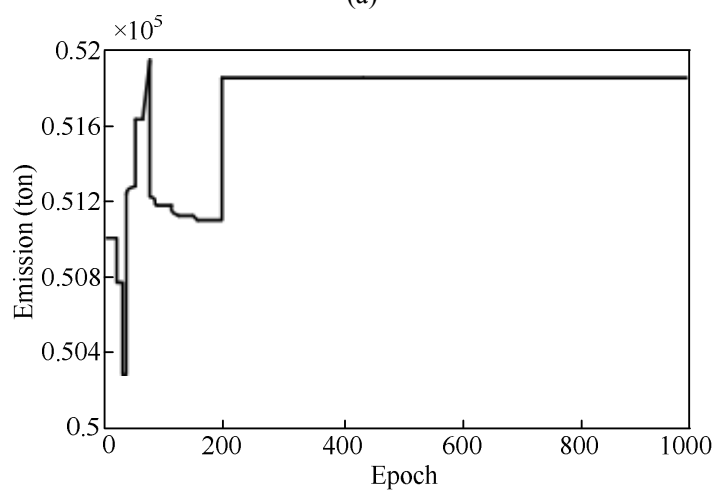

(b)

Figure 7. Effect of only cost in fitness function.

From these results, cost and emission can be balanced when they are simultaneously considered in the fitness function. Namely, generating units and gridable EVs should be simultaneously scheduled properly. It is demonstrated that the proposed multilayer grid with $\mathrm{V} 2 \mathrm{G}$ is feasible and can reduce operation cost and emission.

\section{CONCLUSIONS}

In this paper, a new multilayer framework has been developed to implement the concept of V2G. An intragrid is introduced to improve the constructions and functions of the previously proposed V2G framework. This framework fully utilizes the characteristics of gridable EVs with bidirectional power flows. Once they are connected to the power grid, charging and discharging can extend to taking energy from the grid and feeding back energy to the grid respectively. The aggregation of EVs can be resources that provide capacity and energy service to achieve peak load shaving during daytime, or loads that work on leveling the off-peak load at night. The main task of the aggregator is to collect a certain number of EVs which have big enough capacity to influence the grid, and artfully control the power flow in the intragrid and intergrid. Based on the proposed V2G framework, cost-emission optimization analysis is carried out since V2G can reduce the 
usage of small and expensive generating units and emissions. PSO is used to achieve the objective of minimizing the operation cost and emission as well as improving system reserve and reliability. According to the simulation results, it is demonstrated that the proposed multilayer grid with $\mathrm{V} 2 \mathrm{G}$ is feasible and can reduce operation cost and emission.

\section{ACKNOWLEDGMENT}

This work was supported by a grant (Project code: 200907176028) from the Committee on Research and Conference Grants, The University of Hong Kong, Hong Kong Special Administrative Region, China.

\section{REFERENCES}

[1] C.C. Chan and K.T. Chau, Modern Electric Vehicle Technology, Oxford: Oxford University Press, 2001.

[2] K.T. Chau and C.C. Chan, "Electric vehicle technology - a timely course for electrical engineering students," International Journal of Electrical Engineering Education, Vol. 35, No. 3, July 1998, pp. 212-220.

[3] K.T. Chau, Y.S. Wong and C.C. Chan, "EVSIM - a PC-based simulation tool for electric vehicle technology course," International Journal of Electrical Engineering Education, Vol. 37, No. 2, April 2000, pp. 167-179.

[4] K.T. Chau, Y.S. Wong and C.C. Chan, "An overview of energy sources for electric vehicles," Energy Conversion and Management, Vol. 40, No. 10, July 1999, pp. 1021-1039.

[5] K.T. Chau and Y.S. Wong, "Hybridization of energy sources in electric vehicles," Energy Conversion and Management, Vol. 42, No. 9, June 2001, pp. 1059-1069.

[6] K.T. Chau and Y.S. Wong, "Overview of power management in hybrid electric vehicles," Energy Conversion and Management, Vol. 43, No. 15, June 2002, pp. 1953-1968.

[7] Y.S. Wong, K.T. Chau and C.C. Chan, "Optimal subsidizing policy to promote electric vehicles in Hong Kong," Journal of Asian Electric Vehicles, Vol. 1, No. 2, December 2003, pp. 479-482.

[8] Y.S. Wong, K.T. Chau and C.C. Chan, "Load forecasting of hybrid electric vehicles under real time pricing," Journal of Asian Electric Vehicles, Vol. 3, No. 2, December 2005, pp. 815-818.

[9] Y.S. Wong, K.T. Chau and C.C. Chan, "Battery sizing for plug-in hybrid electric vehicles," Journal of Asian Electric Vehicles, Vol. 4, No. 2, December 2006, pp. 899-904.

[10] C.C. Chan and K.T. Chau, "An overview of power electronics in electric vehicles," IEEE Transactions on Industrial Electronics, Vol. 44, No. 1, February 1997, pp. 3-13.

[11] S.Z. Jiang, K.T. Chau and C.C. Chan, "Performance analysis of a new dual-inverter pole-changing induction motor drive for electric vehicles," Electric Power Components and Systems, Vol. 30, No.1, January 2002, pp. 11-29.

[12] S.Z. Jiang, K.T. Chau and C.C. Chan, "Spectral analysis of a new sixphase pole-changing induction motor drive for electric vehicles," IEEE Transactions on Industrial Electronics, Vol. 50, No. 1, February 2003, pp. 123-131.

[13] S.Z. Jiang, K.T. Chau and C.C. Chan, "Harmonic reduction in dc-link current of a dual-inverter pole-changing induction motor drive for electric vehicles," Electric Power Components and Systems, Vol. 31, No. 11, November 2003, pp. 1063-1081.

[14] K.T. Chau and Z. Wang, "Overview of power electronic drives for electric vehicles," HAIT Journal of Science and Engineering - B: Applied Sciences and Engineering, Vol. 2, No. 5-6, December 2005, pp. 737-761.
[15] M.S.W. Chan, K.T. Chau and C.C. Chan, "Effective charging method for ultracapacitors," Journal of Asian Electric Vehicles, Vol. 3, No. 2, December 2005, pp. 771-776.

[16] M.S.W. Chan, K.T. Chau and C.C. Chan, "A new switched-capacitor inverter for electric vehicles," Journal of Asian Electric Vehicles, Vol. 4, No. 2, December 2006, pp. 905-909.

[17] M.S.W. Chan and K.T. Chau, "A switched-capacitor boost-multilevel inverter using partial charging," IEEE Transactions on Circuit and Systems II - Express Briefs, Vol. 54, No. 12, December 2007, pp. 11451149.

[18] W. Kempton and T. Kubo, "Electric-drive vehicles for peak power in Japan," Energy Policy, Vol. 28, No. 1, January 2000. pp. 9-18.

[19] J. Tomic and W. Kempton, "Using fleets of electric-drive vehicles for grid support," Journal of Power Sources, Vol. 168, No. 2, June 2007, pp. 459-468.

[20] W. Kempton and J. Tomic, "Vehicle-to-grid power implementation: From the stablizing the grid to supporting large-scale renewable energy," Journal of Power Sources, Vol. 144, No. 1, June 2005, pp. 280-294.

[21] C. Guille and G. Gross, "A conceptual framework for the vehicle-to-grid (V2G) implementation," Energy Policy, Vol. 37, No. 11, November 2009, pp. 4379-4390.

[22] W.X. Shen, C.C. Chan, E.W.C. Lo and K.T. Chau, "A new battery available capacity indicator for electric vehicles using neural network," Energy Conversion and Management, Vol. 43, No. 6, April 2002, pp. 817-826.

[23] W.X. Shen, C.C. Chan, E.W.C. Lo and K.T. Chau, "Adaptive neurofuzzy modeling of battery residual capacity for electric vehicles," IEEE Transactions on Industrial Electronics, Vol. 49, No. 3, June 2002, pp. 677-684.

[24] K.T. Chau, K.C. Wu, C.C. Chan and W.X. Shen, "A new battery capacity indicator for nickel-metal hydride battery powered electric vehicles using adaptive neuro-fuzzy inference system," Energy Conversion and Management, Vol. 44, No. 13, August 2003, pp. 2059-2071.

[25] K.T. Chau, K.C. Wu and C.C. Chan, "A new battery capacity indicator for lithium-ion battery powered electric vehicles using adaptive neurofuzzy inference system," Energy Conversion and Management, Vol. 45, No. 11-12, July 2004, pp. 1681-1692.

[26] M.S.W. Chan, K.T. Chau and C.C. Chan, "Design and implementation of neural network based capacity indicator for lithium-ion battery," Journal of Asian Electric Vehicles, Vol. 2, No. 2, December 2004, pp. 627-632.

[27] W.X. Shen, K.T. Chau, C.C. Chan and E.W.C. Lo, "Neural network based residual capacity indicator for nickel-metal hydride batteries in electric vehicles," IEEE Transactions on Vehicular Technology, Vol. 54, No. 5, September 2005, pp. 1705-1712.

[28] W. Kempton and J. Tomic, "Vehicle-to-grid power fundamentals: Calculating capacity and net revenue," Journal of Power Sources, Vol. 144, No. 1, June 2005, pp. 268-279.

[29] K.T. Chau and C.C. Chan, "Emerging energy-efficient technologies for hybrid electric vehicles," Proceedings of IEEE, Vol. 95, No. 4, April 2007, pp. 821-835.

[30] K.T. Chau, C.C. Chan and C. Liu, "Overview of permanent-magnet brushless drives for electric and hybrid electric vehicles," IEEE Transactions on Industrial Electronics, Vol. 55, No. 6, June 2008, pp. 2246-2257.

[31] X. Zhang, K.T. Chau and C.C. Chan, "Overview of thermoelectric generation for hybrid vehicles," Journal of Asian Electric Vehicles, Vol. 6, No. 2, December 2008, pp. 1119-1124.

[32] A.Y. Saber and G.K. Venayagamoorthy, "Intelligent unit commitment with vehicle-to-grid - A cost-emission optimization," Journal of Power Sources, Vol. 195, No. 3, February 2010, pp. 898-911.

[33] M.A. Abido, "Multiobjective evolutionary algorithms for electric power dispatch problem," IEEE Transactions on Evolutionary Computation, Vol. 10, No. 3, June 2006, pp. 315-329. 